\title{
AS TAREFAS ESCOLARES E O ENSINO DESENVOLVIMENTAL ${ }^{1}$
}

\author{
Made Júnior Miranda ${ }^{2}$
}

\begin{abstract}
RESUMO
Este texto buscou reunir contribuições sobre os procedimentos pedagógicos e didáticos no contexto do desenvolvimento das "tarefas escolares". O estudo foi com base da teoria histórico-cultural da atividade dos psicólogos da educação russa expressados na Teoria do Ensino Desenvolvimental de Vasili V. Davídov. A demanda está centrada na ideia de que as 'tarefas escolares' são ações que se inserem no próprio processo de ensino valorizando a sua essência dialética e transformadora do potencial dos indivíduos em constante desenvolvimento. A finalidade foi incitar os leitores no sentido produzir ideias capazes de influenciar consideravelmente no contínuo processo transformador que regula o ato de ensinar e de aprender no campo prático. A revisão e análise de literatura discutiu as tarefas no contexto escolar e os pressupostos da Teoria do Ensino Desenvolvimental na relação com as tarefas escolares. Concluiu-se que o trabalho com as tarefas no ensino desenvolvimental é uma perspectiva superadora de educação e acontece vinculado a uma estrutura de atividade humana que integra indissociavelmente o saber, o aluno e o professor na atividade propositiva.
\end{abstract}

Palavras-chave: Tarefas; Atividade; Ensinagem; Desenvolvimental

\section{TASKS EDUCATIONAL AND DEVELOPMENTAL EDUCATION}

\begin{abstract}
This paper sought to gather input on the teaching and learning procedures in the development of "homework". The study was based on the historical-cultural theory of Russian education psychologists of activity expressed in Developmental Education Theory Vasili V. Davidov. Demand is focused on the idea that the 'homework' are actions that fall within the proper teaching process valuing its dialectical essence and transforming the potential of individuals in constant development. The purpose was to encourage readers towards producing ideas that can influence considerably the ongoing transformative process that regulates the act of teaching and learning in the practical field. The review and literature review discussed the tasks in the school context and assumptions of the Theory of Developmental Education in relation to schoolwork. It was concluded that the work with the tasks in developmental education is a surpassing perspective of education and happens bound to a human activity structure that integrates inseparably knowledge, the student and the teacher in purposeful activity.
\end{abstract}

Keywords: Tasks; Activity; teaching and learning; developmental 


\section{Introdução}

[...] o como se ensina depende de saber como os indivíduos aprendem... J. C. Libâneo.

Basicamente as avaliações do sistema escolar brasileiro indicam que temos dificuldades na preparação dos estudantes da escola fundamental para a compreensão de textos simplórios (ROSSI E DE PAULA, 2012). Logo, como os estudantes brasileiros não se sentem suficientemente interessados pela leitura, eles não desenvolvem o hábito de ler, que por sua vez cria uma dificuldade para entender o enunciado de questões de matemática que exijam interpretação de texto e raciocínio lógico, caracterizando, portanto, problemas na elaboração de cálculos aritméticos de operações essenciais e um ciclo vicioso (SADOVSKY, 2007; CARVALHO, 2015).

Para além dos relatórios pontuais de pesquisadores da educação brasileira sobre o nível de desenvolvimento da aprendizagem dos alunos nas escolas das redes de ensino, outros instrumentos de avaliação (PISA, SAEB, ENEM, Censo Escolar, Provinha Brasil etc.) têm corroborado com a apresentação dos baixos rendimentos dos estudantes nos conteúdos básicos de Leitura, Matemática e Ciências Naturais (INEP, 2015). Embora os instrumentos de avaliação institucionais estejam inseridos na temática dos novos modos de regulação da educação que demarcam uma relação circular entre conhecimento e política, ou seja, "[...] como instrumento de política, produz conhecimento e, como instrumento científico, produz política" (COSTA E AFONSO, 2009, p.1), eles afloram as discussões sobre a relação do triângulo didático formado entre o conhecimento, o aluno e o professor mediador (LIBÂNEO, 2009), quer seja sobre qual tem sido o modo de ensinar e o modo de aprender que estamos desenvolvendo para promover o desenvolvimento humano.

É sabido que a necessidade do estudo de metodologias com análises pedagógicas e didáticas das questões educacionais é hoje uma temática que merece maior atenção nos campos intelectual e investigativo da educação. Nas últimas três décadas os estudos de caráter sociológicos e políticos têm despertado um maior interesse dos pesquisadores, sobretudo em função dos enfoques muito distantes das atividades que acontecem no cotidiano das "salas de aulas" e dos alunos concretos que lá estão sujeitos do processo de ensino-aprendizagem (LIBÂNEO, 2009). Este contexto denota que a didática tem perdido espaço tanto como prática quanto campo de conhecimento e tem sido atribuído a ela um status de prática de ensino tradicional, e que, por sua vez, não seria condizente com os anseios de transformação da sociedade contemporânea pela educação (CANDAU, 2012).

Assim, este texto busca valorizar a didática, não como uma prática apaziguadora do ensino tradicional, mas "[...] como uma epistemologia, um corpo de conhecimentos oriundos de diferentes campos que, tomados em seu conjunto, permitem planejar o ensino e agir no contexto da sala de aula" (FREITAS E ROSA, 2015, p.616). Trata-se da didática como teoria e prática do ensino, a serviço da prática docente e da aprendizagem dos alunos, promovendo mudanças qualitativas importantes e mútuas existentes entre os sujeitos que se propõem a ensinar e os que estão dispostos a aprender. Por conseguinte, o conceito de didática que nos orienta tem como premissa a análise da natureza dos conteúdos em função de seu ensino, sendo desenvolvido com alunos determinados e em contextos socioculturais específicos (LENOIR, 1996).

Mais pontualmente, pretendemos aqui reunir algumas contribuições sobre os procedimentos pedagógicos e didáticos no contexto do desenvolvimento das "tarefas escolares", a partir do entendimento de que a intervenção pedagógica pelo ensino é imprescindível para o desenvolvimento cognitivo, afetivo e moral do aprendiz 
(VIGOTSKI, 1994). Neste caso, o professor tem papel ativo e intencional na promoção da aprendizagem dos alunos, mediando as relações com os objetos do conhecimento e atuando na formação de ações mentais e no aprimoramento da capacidade de reflexão sobre os objetos de análise.

Para desenvolver este estudo trabalhamos com os referenciais teóricos de aprendizagem e desenvolvimento alicerçados na base da Teoria Histórico Cultural da Atividade de Lev S. Vigotski, Alexei Leontiev e outros psicólogos da educação russa que entendemos estar bem expressada na Teoria do Ensino Desenvolvimental de Vasili V. Davídov, onde a aprendizagem possibilita ao aluno internalizar a experiência humana constituída socialmente e culturalmente, organizada em teorias, capacidades, habilidades, hábitos, valores, por mediações do conhecimento em diferentes condições culturais, sociais, ambientais, regionais etc.

O termo "tarefa" faz parte do cotidiano de vários sujeitos do contexto de ensino e aprendizagem, mas as suas conjunturas podem se diferir substancialmente quando nós estabelecemos um determinado marco teórico. Assim, procuramos aqui explorar um sentido pedagógico e didático para as tarefas escolares valorizando a sua essência dialética e transformadora do potencial dos indivíduos em constante desenvolvimento.

A demanda deste estudo está centrada na ideia de que as 'tarefas escolares' não são simplesmente as ações feitas após os professores terem ensinado os conteúdos aos alunos, mas sim, algo que se insere no próprio processo de ensino (DAVÍDOV, 1986). Por esta linha de pensamento, a tarefa é mesmo necessária ao ensino, mas não se trata de deixar o aluno 'aprender por si só', pois estamos pensando em uma metodologia de trabalho dos envolvidos que dê conta de apresentar o novo conhecimento a ser aprendido e ao mesmo tempo consiga solicitar dos alunos a compreensão correspondente aos processos que originaram e representam o estado de desenvolvimento do objeto do conhecimento em análise.

Didaticamente falando, a elaboração das tarefas para os alunos deve levar em conta os aspectos lógicos e epistemológicos dos conteúdos a serem ensinados, o que vale dizer que o professor além de saber o conteúdo como conhecimento produzido cientificamente, ele necessita conhecê-lo como produto e como processo, percebendo com muita clareza o caminho de raciocínio que o cientista percorreu até chegar naquele patamar de entendimentos sobre o objeto em estudo (FREITAS; ROSA, 2015). Nesta perspectiva, o aprendizado humano pressupõe uma natureza social específica e um processo de apropriação do conhecimento socialmente acumulado, através do qual os escolares adentram na vida intelectual daqueles que organizaram um determinado saber, possibilitando um desvendamento das ações mentais realizadas pelo cientista na produção do conhecimento (VIGOTSKI, 2007).

Após esta introdução, organizamos este trabalho de revisão e análise de literatura em dois tópicos. O primeiro discute as tarefas no contexto escolar e o segundo os pressupostos da Teoria do Ensino Desenvolvimental na relação com as tarefas escolares. A finalidade é incitar os leitores no sentido produzir ideias capazes de influenciar consideravelmente no contínuo processo transformador que regula o ato de ensinar e aprender no campo prático. 


\section{Desenvolvimento}

\subsection{As tarefas no contexto escolar}

A palavra 'tarefa', no contexto das atividades escolares, tem recebido algumas denominações como "para casa", "dever de casa" ou "lição de casa" para designar um recurso pedagógico auxiliar do processo de aprendizagem (FERNANDEZ ET AL., 2014). É uma categoria de estudo do fazer pedagógico que solicita a participação de alguns agentes, entre eles, a escola e suas concepções, metodologias e mecanismos reguladores; os professores e suas manifestações pedagógico-didáticas; os estudantes como sujeitos centrais do fazer pedagógico e os fatores que estão a influenciar no seu processo de desenvolvimento; a sociedade maior representada pelos pais, responsáveis e todos aqueles que são "chamados" a se envolverem na demanda das tarefas escolares para coaptar de alguma forma as suas convicções e incertezas sobre a missão de educar.

A palavra "tarefa" vem de "tariha" de origem árabe que se refere ao "conjunto de trabalhos impostos a uma pessoa". Para Castro (2006), significa também trabalho que o aluno deve concluir num certo tempo normalmente estipulado pelo professor. Observamos que etimologicamente esta palavra traz consigo um legado das pedagogias autoritárias (FREIRE, 1967) que ainda hoje é insurgente nas relações didáticas de aprendizagem. Conforme verificado por Fagundes e Mattos (2009) e Castro (2006, 2007) na realidade escolar há uma naturalização da ideia de que a tarefa escolar representa um ofício do aluno e também um dever a ser cumprido por ele.

Seja como tarefa escolar ou como dever de casa, tem sido solicitado aos estudantes das escolas brasileiras de ensino formal a realização dos exercícios escritos, leituras, consultas bibliográficas, pesquisas, trabalhos em grupos e outras atividades fora do período regular de aulas, compondo o rol de afazeres curriculares que atribui à escola uma possível eficiência na efetivação da sua proposta pedagógica (RESENDE, 2011). Para a autora que corrobora com os estudos de Franco (2002), Carvalho (2001), Nogueira (2002; 2005) e Carvalho e Burity (2005), o encaminhamento do "para casa", grosso modo, tem um consenso parental e da sociedade em relação a importância da prescrição das tarefas para serem realizadas nos domicílios e com o acompanhamento de outrem, sendo considerado um fator responsável pelo sucesso escolar. Contudo, a eficácia deste recurso pedagógicodidático não está bem clara cientificamente, haja vista a pequena e diversificada produção científica brasileira em torno da questão que se distribui entre pesquisas psicológicas, didáticas e sociológicas, demarcadas, sobretudo, pela escassez de referenciais teóricos organizados para fundamentar as possíveis análises contextuais.

Em pesquisas de Carvalho e Burity (2005), que investigou as visões de mães e professoras sobre as tarefas escolares, e de Fernandez et al. (2014) que pesquisou o envolvimento parental na tarefa escolar, constatou-se que inicialmente as mães consideraram as tarefas como um recurso didático imprescindível para o desenvolvimento dos escolares, mas com o detalhamento das questões denotaram suas preocupações com o estresse causado pela atividade que muitas vezes decorre de fatores como: do total desconhecimento do assunto tratado na tarefa; da sua aprendizagem insuficiente para poder ajudar o escolar com qualidade; da compreensão da própria objetividade da tarefa; entre outros fatores como tempo disponível, quantidade de filhos em processo de escolarização e outras atribuições domésticas e laborais que podem interferir no sucesso das interferências dos 'ajudantes-de-tarefa' juntos aos aprendizes.

Outro fato, não menos grave, que transcende a opção por uma determinada matriz epistemológica que orienta o fazer pedagógico e os consensos sobre seu significado como 
recurso didático, se refere a objetividade das tarefas no espaço formativo. Castro (2007) salientou no seu estudo que as tarefas que tão bem representam um recurso didático peculiar e promovedor da atividade pedagógica de 'ensinagem' não têm proporcionado a 'aprendizagem' aos alunos, além de descaracterizá-los como sujeitos produtores de saberes. Isto, se deve ao fato de que a tarefa "[...] acaba por se tornar um engodo, uma vez que, nem professora e nem alunos entendem essencialmente o seu significado para a formação dos mesmos (CASTRO, 2007, p. 88)". Ou seja, o que podemos pensar sobre uma orientação teórica e metodológica capaz de atribuir o sentido essencial deste recurso pedagógico e didático (tarefas) no processo de ensinagem?

Esta é uma questão que acreditamos que deve ser tratada com certo melindre, pois, talvez seja justamente a falta de critérios fundamentados o motivo de muitos percalços pelos quais passa o nosso sistema educacional brasileiro. $\mathrm{O}$ que se pretende aqui é chegar a uma organização de conhecimentos que possam ser empenhados no fazer pedagógico e didático, contribuindo para práxis educacional. Passaremos então a fazer uma maior aproximação com os pressupostos da Teoria do Ensino Desenvolvimental.

\subsection{A Teoria do Ensino Desenvolvimental}

A Teoria do Ensino Desenvolvimental no contexto da educação contemporânea pode dar uma relevante contribuição diante das exigências postas à escola, em especial a elevação do nível de pensamento dos escolares e a interiorização de mediações culturais que possibilitam aos alunos a autorregulação de sua própria atividade (MIRANDA, 2013). O surgimento da Teoria do Ensino Desenvolvimental está associado às reformas na base da educação russa nos anos 1920-30 quando psicólogos soviéticos e pedagogos, entre eles Vigotski, Luria, Leontiev, Rubinstein e seus seguidores começaram a investigar o problema da vinculação entre os sistemas de educação e o desenvolvimento da mente da criança, a partir dos princípios do materialismo dialético e histórico.

De cunho dialético, a Teoria do Ensino Desenvolvimental de Davídov justifica a natureza históricossocial e o caráter mediador da atividade humana em geral e, em particular, da atividade mental e do processo cognitivo dos alunos. Logo, o elemento nuclear da tese de Davídov está na compreensão de que o ensino e a educação determinam os processos de desenvolvimento mental dos sujeitos, de suas capacidades e qualidades mentais. Assim, através da apropriação dos conhecimentos socialmente construídos, o indivíduo reproduz em si mesmo as formas histórico-sociais da atividade aprendida.

Conforme escreveu o autor:

[...] formar nas crianças representações materialistas firmes para produzir nelas o pensamento independente e melhorar significativamente a formação artística e estética, elevar o nível ideológico e teórico do processo de ensino e educação, expor claramente os conceitos básicos e principais ideias das disciplinas escolares, erradicarem quaisquer manifestações de formalismo no conteúdo e métodos de ensino e no trabalho de formação e aplicar amplamente as formas e métodos ativos de ensino, etc. (DAVÍDOV, 1986, p. 44).

Para Davídov, o ensino desenvolvimental, facilita o desenvolvimento da mente do aluno, ajudando-o a pensar teoricamente e consequentemente desenvolvendo a sua personalidade. A função do ensino, neste caso, é estimular nos alunos as capacidades cognitivas necessárias para a assimilação e utilização com sucesso dos conhecimentos estudados, podendo com autonomia fazer as devidas relações entre as coisas, fenômenos, 
informações, situações etc.

De acordo com Libâneo (2009), quando analisa as objetivações contemporâneas da escola de Vigotski e a Teoria do Ensino Desenvolvimental de Davídov ele coloca que o ensino mais coerente com o mundo da ciência, da tecnologia, dos meios de comunicação tem as seguintes características:

[...] o conteúdo da atividade de aprendizagem é o conhecimento teóricocientífico e os atos mentais que lhe correspondem. [...] O pensamento teórico se forma pelo domínio dos processos de investigação, dos procedimentos lógicos do pensamento, relacionados com um conteúdo. [...] A melhor metodologia de ensino, em qualquer disciplina, é aquela que ajuda os estudantes, todos os dias e em todas as aulas, a pensar teoricamente, ou seja, cientificamente, com os conteúdos e métodos da ciência ensinada. Compromisso com o conhecimento científico (LIBÂNEO, 2009, p. 17).

Explica Davídov (1988), que o ensino de determinada ciência deve fazer uma correspondência a essa ciência e seus objetos. Assim, o planejamento do ensino se inicia com a análise do conteúdo, identificando o seu conceito nuclear e consequentemente sua relação geral estabelecida cientificamente na prática social e histórica. O processo de identificar o conceito de determinado objeto de estudo, promove um desvendamento do caminho percorrido pelo cientista para concebê-lo. A isto, Davídov chamou de método genético. Pois é justamente em função deste raciocínio que o autor entende que a aprendizagem deve ser na forma de resolução de problemas e o ensino com pesquisa, onde, o professor tem o papel de mediar interferindo ativamente nos processos mentais dos alunos e produzindo novas formações da atividade mental por meio dessa interferência.

\subsection{Tarefas de aprendizagem e o ensino desenvolvimental}

A tarefa de aprendizagem a qual nos referimos no ensino desenvolvimental é aquela que pelos meios definidos na relação dialética entre professor, aluno e objeto do conhecimento, consegue resolver a necessidade existente no aluno em consonância com sua capacidade de receber e executar as respectivas ações de aprendizagem. Essa associação entre o assunto a ser aprendido e os motivos do aluno que aprende, constitui conforme Chaiklin (2003) o coração do ensino desenvolvimental.

Como ponto de partida para que as tarefas de aprendizagem atinjam o seu propósito Davídov (1999) sugere que devemos despertar nos alunos a consciência para a necessidade de aprenderem os conteúdos de trabalho. Ressalta o autor que o alcance dos objetivos decorrentes da organização da atividade de aprendizagem se dará dentro de uma subordinação à estrutura da atividade.

No sentido de promover uma melhor visualização da estrutura da atividade humana proposta por Davídov vamos imaginar um estudante que está desejoso de aprender a tocar violão. O simples fato do desejo de aprender a dar sonoridade a um instrumento musical (violão) já implica na satisfação de alguma necessidade que pode ter ocorrido por diferentes circunstâncias da vida do sujeito, mas que de fato vai configurar a razão, vai dar sentido a todo esforço que ele empreenderá no processo de aprendizagem. Dizemos que ele tem uma motivação intrínseca ou teve uma motivação extrínseca que se converteu em intrínseca, ele encontrou um motivo para aprender. Logo, o verdadeiro motivo transcende a esfera material e está mais precisamente no campo espiritual, isto é, não serão motivos apenas externos ao aluno, mas também internos. O motivo mais apropriado para ser 
cultivado pelo aprendiz de violão será o de ser melhor a cada momento, apresentando cada vez mais novos domínios que nunca conseguiu demonstrar nesta arte. Outros motivos como agradar aos amigos, passar a ideia de um jovem talentoso e prendado etc., não devem ser centrais no processo, cabendo ao professor intermediar as atitudes deste aluno para que ele não se descole do conceito mais amplo do que vem a ser um músico competente (DAVÍDOV, 1999).

Quando o aprendiz começar a fazer 'coisas' no sentido de aprender o ofício desejado ele se direcionou para as atividades de aprendizagem. Estas atividades propositais diferentemente das atividades do cotidiano são determinadas por seu objetivo, tornando-se tarefas de aprendizagem. Para atingir o objetivo são necessárias várias ações conexas que consideram a dinâmica do caráter de aprendizagem e o de autoria de um conhecimento desenvolvido histórico e culturalmente. Com a mediação deste conhecimento pelo professor, o estudante de violão precisa desvendar as ações mentais necessárias compreendidas no domínio desta arte.

Todas as ações decorridas dos objetivos e das tarefas são constituídas de operações. Essas operações dão materialidade às ações à medida que as tornam mais completas e concretas e possibilitam a contemplação dos objetivos. No caso específico da aprendizagem de tocar violão, as operações mais comuns se referem as empunhaduras e técnicas de manuseios do instrumento, seus argumentos teóricos lógicos-racionais estabelecidos pelos estudiosos da área; as notas musicais e as possibilidades próprias do instrumento entre outras que caberá a um professor especialista organizá-las com propriedade e introduzi-las no caminho a ser percorrido pelo aluno, através de interações e comunicação, utilizando materiais pedagógicos-didáticos visando oportunizar na mente do aluno a reprodução de todo processo criativo original do conhecimento em estudo. Freitas e Rosa, (2015, p.621) entendem que o professor precisa "[...] conhecer o modo investigativo pelo qual o conhecimento foi produzido, pois é aí que se situa o modo de pensar, analisar e compreender o objeto a ser ensinado a seus alunos".

Outro elemento fundamental, componente da estrutura da atividade de Davídov (1999), para a satisfação plena da necessidade do aluno de aprender a tocar violão são as condições concretas disponíveis para que as atividades aconteçam, podendo ser a existência o próprio instrumento musical, o ambiente propício para aprendizagem, a carga horária de trabalho etc. e todo aparato peculiar e essencial imprescindível para se efetivar eficazmente os objetivos.

Assim Davídov propõe que a proposta didática fundamentada na Teoria do Ensino Desenvolvimental mantenha invariável a estrutura de atividade humana no trabalho com o conhecimento, mas no âmbito das tarefas há que se considerar diferenciações de ordem lógica, histórica e epistemológica nas ações de aprendizagem em função da área de conhecimento, da especificidade dos conteúdos e características dos alunos (FREITAS E ROSA, 2015). Portanto, o que permanece como estrutura de solução de tarefas de aprendizagem (solução de problemas) no contexto da estrutura de atividade do ensino desenvolvimental é o desenvolvimento do pensamento teórico do aluno por meio da apropriação do objeto de estudo, incluindo a descoberta de sua estrutura geral, a formação de conceitos e a sua transformação mediante a generalização teórica.

Esta trajetória para assimilação do conhecimento se processará pela condução do movimento do pensamento dos alunos de um plano geral para um plano particular, ou seja, eles a princípio com ajuda de outros e depois sozinhos procurarão identificar o "núcleo" essencial do objeto de estudo para de posse desta base (ou meio) poderem deduzir outras particularidades do mesmo objeto. Quando os alunos conseguem por meio da criação de seus referenciais perceberem a relação geral e principal do objeto em análise eles passam a 
ter melhores condições de externalizarem seus conceitos pelas abstrações que processaram (internalizaram) no estudo. No caso do aluno que aprende a toar violão, não será necessário ensiná-lo a tocar todas as músicas, pois com os conhecimentos básicos essenciais e nucleares dessa arte ele deverá ser capaz de reproduzir várias partituras diferentes, além de poder se tornar um compositor de músicas até então inéditas (DAVÍDOV, 1999).

No desenvolvimento do processo de aprendizagem Davídov (1983) propõe que haja uma ação de controle sobre as atividades de aprendizagem no sentido de melhorar os resultados da assimilação dos conteúdos pelos alunos. As ações de controle se iniciam sob a responsabilidade do professor e caminham para o desenvolvimento da autonomia dos alunos, desenvolvendo neles as condições para que consigam comparar qualitativamente os resultados de suas ações com os de outras situações.

Através da proposição de confrontos com situações problemas diversas e variadas, mas que exigem para a sua solução a utilização de ações teórico-práticas de mesmo princípio lógico de raciocínio, o professor poderá verificar o nível de apreensão teórica do aluno sobre o objeto de estudo, isto se dará pela constatação do princípio da generalização, ou seja da utilização de um conceito geral e abrangente sendo usado para resolver problemas particulares e de várias ordens.

O trabalho mental esperado pelo desenvolvimento da tarefa de aprendizagem envolvendo o problema e o objeto do conhecimento deve ser encaminhado para que o aluno tenha as ações mentais que correspondem a esse novo conhecimento, dando a ele as condições de recriar e criar novas relações de pensamento diferentes e mais lógicas do que aquelas que ele possuía antes da atividade de aprendizagem (DAVÍDOV, 1986).

Assim o papel daquele que propõe e medeia o desenvolvimento da tarefa (professor) adquire uma importância decisiva na aprendizagem, onde

[...] o professor necessita ter para si a lógica investigativa do objeto a ser ensinado, implica necessariamente uma integração entre a lógica epistemológica do conteúdo e o tratamento pedagógico-didático desse conteúdo, na perspectiva da atividade criativa (recriativa) do aluno na relação de aprendizagem com o objeto. [...] Em outras palavras, o professor precisa conhecer o modo investigativo pelo qual $\mathrm{o}$ conhecimento foi produzido, pois é aí que se situa o modo de pensar, analisar e compreender o objeto a ser ensinado a seus alunos (FREITAS E ROSA, 2015, p.621).

Portanto investigar como acontecem as tarefas na perspectiva do ensino desenvolvimental consiste num estudo meticuloso, pois a processualidade da proposta de Davídov se preocupa com a superação da aprendizagem do tipo imediata e superficial que ocorre na maioria das escolas, onde tem sido confundida a atividade de aprendizagem com o "colocar em atividade" esperando que os alunos simplesmente aprendam (SOARES, 2007). De fato os alunos podem trabalhar o conhecimento científico por meio da manipulação e operação com materiais e objetos considerados pedagógicos, mas como Soares analisou é preciso certificar se esta metodologia permitiu ao aluno desvelar a origem do objeto, suas relações históricas, sua gênese; se nesse processo o aluno desenvolveu o seu pensamento teórico e se ele percebeu as diferentes relações presentes no objeto aprendido; ou se ele simplesmente continuou na empiria no tratamento com o objeto. 


\section{Considerações finais}

Entendemos como Davídov (1988) que a tarefa que está posta na prática pedagógica da escola seja, sobretudo, exercer uma influência positiva sobre o desenvolvimento das potencialidades dos alunos, criando as condições necessárias para eles desenvolverem o pensamento teórico-científico e as suas capacidades próprias de raciocínio com os conteúdos e métodos da ciência ensinada. Estas são solicitações imprescindíveis do mundo contemporâneo que está caracterizado, cada vez mais, pelo desenvolvimento da ciência, da tecnologia e dos meios de comunicação. Assim é possível identificar na Teoria do Ensino Desenvolvimental uma organização de pressupostos que consideramos significativos para aqueles que se propõem a ensinar numa perspectiva superadora de educação.

Em sendo a Teoria do Ensino Desenvolvimental um conjunto de conhecimentos destinados a alavancar o desenvolvimento das potencialidades mentais superiores dos estudantes, nós imaginamos que a sua aplicação favorece uma escola que prioriza o conhecimento, isto é, o domínio dos conteúdos e a formação das capacidades cognitivas dos alunos. Como o nosso sistema escolar segue o modelo neoliberal de educação de massas (NÓVOA, 2009; MIRANDA, 2005; LIBÂNEO, 2004; CHARLOT, 2005; FRIGOTTO, KUENZER, GENTILI, 2013; entre outros) assentado, antes de tudo, na retórica da "educação inclusiva", é provável que este fator seja um dos entraves para o trabalho pouco alentador, nas escolas, com perspectivas de ensino mais centradas no desenvolvimento intelectual dos alunos. Como coloca Nóvoa (2009) as politicas estão encaminhando a formação de uma escola da cidadania e participação para acolher os pobres e outra escola focada na aprendizagem e nas tecnologias destinada a formar os filhos dos ricos. Obviamente que a escola dos pobres contempla a maioria absoluta!

Este cenário está sendo posto aqui porque o desenvolvimento de um processo formativo na perspectiva do ensino desenvolvimental requer um pensamento educacional inclusivo fundamentado na ideia de que o elemento nuclear da escola é a didática e a aprendizagem do pensar e do aprender (LIBÂNEO, 2004). Quando analisamos o nosso sistema escolar observamos que há paradoxos conceituais inviabilizando a democratização da aprendizagem. Como citou Boneti (2006, p. 113) "[...] as nossas instituições públicas em geral não absorveram a evolução conceitual e teórica processadas na academia em relação as significações envolvidas no discurso da educação inclusiva". Isto indica que há um entendimento de exclusão social se referindo somente à inquietação geral decorrente do flagelo social e se ocupando das vítimas deste processo, que a nosso ver caracteriza um equivoco na diferenciação do que vem a ser "educação inclusiva" e "integração" no âmbito educacional escolar (EDLER, 1997).

Portanto, considerando que o modo de trabalhar pedagogicamente com algo depende do modo de trabalhar epistemologicamente, na perspectiva do ensino desenvolvimental, o elemento 'tarefa escolar' não se desenvolve como um recurso pedagógico e didático fragmentado do processo, como um complemento extraclasse capaz de repercutir efeitos formativos consideráveis num contexto de aprendizagem. $\mathrm{O}$ 'dever de casa', ou 'para casa', ou aquelas tarefas que os estudantes levam nos cadernos e livros rotineiramente para serem feitas e apresentadas posteriormente nas salas de aulas, não pode ter como maiores características o reforço da ideia de que aluno vai 'aprender por si só', e em outros casos são tarefas para serem feitas com o auxilio de outras pessoas que nem sempre possuem uma preparação adequada para mediar um conhecimento dentro de uma suposta estrutura de atividade de aprendizagem em andamento.

De fato o envolvimento parental e de outros sujeitos nas relações (didática, de 
estudo e de mediação) do triângulo didático pode vir ser significativa no desenvolvimento dos escolares, mas também pode ser uma prática nefasta, pouco produtiva e nada motivacional dentro de um processo formativo. Isto porque o trabalho com as tarefas no ensino desenvolvimental acontece vinculado a uma estrutura de atividade que integra indissociavelmente o saber, o aluno e o professor na atividade propositiva. Ou seja, a resolução de tarefas de aprendizagem se inicia coletivamente com a aquisição de um "modo geral" para resolver o problema de aprendizagem que inclui o conhecimento teórico, o modo de funcionamento mental, a forma de ação geral e se encerra com a orientação geral de base para o agir individualmente com a generalização e formação dos conceitos. Assim, no pensamento vigotskiano a interferência de uma pessoa na atividade de ensino deve ocorrer por alguém com maiores conhecimentos sobre o objeto em questão e isso valoriza a importância do papel dos mediadores no trabalho com o conhecimento teórico.

Como já disse Davídov o objetivo do ensino é ensinar aos estudantes as competências e habilidades de aprenderem por si mesmos, ou seja, a pensar. Logo, a proposta da elaboração das tarefas de aprendizagem deve conseguir colocar na forma de problemas específicos, algumas situações em que seja necessário o conhecimento da relação geral do objeto, de forma a oportunizar ao aluno a formação das habilidades cognitivas pela generalização dos conceitos. Assim as tarefas devem se prestar consistentemente a ajudar o aluno a interiorizar os modos de pensar, de raciocinar, de investigar e de atuar com os conceitos nucleares que expressam o desenvolvimento científico que a humanidade já alcançou na matéria estudada. De outra forma as tarefas escolares podem estar sendo desenvolvidas desconectadas da base teórica-científica que dá suporte ao desenvolvimento humano.

Entretanto, não é possível aqui desprezarmos as 'tarefinhas' que os jovens escolares levam para suas casas no dia-a-dia com a alegação de que elas estão sendo propostas pelas escolas de forma inócua, aleatória, ou como um pseudo instrumento didático que a escola utiliza para demonstrar ações de controle sobre o seu fazer pedagógico perante os alunos e a sociedade. Grosso modo, sabemos que não há trabalho que não gere um produto e nem produto que não tenha sido gerado pelo trabalho. A nossa preocupação principal está na desconfiança se o formato de tarefas que vem sendo desenvolvido no cotidiano escolar estaria ou não, permitindo ao aluno usufruir do conhecimento e das condições que poderiam promover a potencialização de suas capacidades mentais superiores, aquelas de raciocínio que somente aos seres humanos podem desenvolver.

Neste contexto podemos indagar: o aluno em questão está tendo os meios e as oportunidades de pensar com o modo próprio de pensar e de operar mentalmente com o objeto de estudo nas tarefas que lhe são propostas? Os motivos e objetivos pessoais que o move são considerados no processo de elaboração das tarefas? O contexto sociocultural e institucional onde ele vive e como esse contexto influi na sua aprendizagem e pode ser modificado, serve de parâmetro para projetar o seu desenvolvimento por meio das tarefas? Enfim estas são questões que acreditamos necessitar de maiores investigações e que possuem um potencial de provocar a reflexão dos sujeitos que compartilham as responsabilidades inerentes as tarefas escolares.

\section{Referências}

BONETI, L. W. Análise crítica dos fundamentos teóricos da educação inclusiva. Revista Diálogo Educacional, Curitiba, v. 6, n.17, p. 113-124, jan./abr. 2006. CANDAU, V. M. F. (Org.) Didática Crítica Intercultural: aproximações. Petrópolis: Vozes, 2012. 
CARVALHO, M. E. P. Rethinking family-school relations: a critique of parental involvement in schooling. Mahwah, New Jersey, USA: Lawrence Erlbaum Associates, 2001.

CARVALHO, M. E. P., BURITY, M. H. Dever de casa: visões de mães e professoras. XXVIII Reunião Anual da Anped, Caxambu/MG, out. 2005. Disponível na Internet: http://www.anped.org.br/28/textos. Acessado em 24 de setembro de 2015.

CASTRO, P. de A. Controlar pra quê? Uma análise etnográfica da interação professor e aluno na sala de aula. Dissertação - Mestrado em Educação pela Universidade do Estado do Rio de Janeiro. Rio de Janeiro, 2006.

Oficio do Aluno: uma análise etnográfica da tarefa do aluno na sala de aula. Projeto apresentado no Programa de Pós-graduação da Universidade do Estado do Rio de Janeiro/ PROPED-UERJ, como pré-requisito para Doutoramento, 2007.

CHAIKLIN, S. The zone of proximal development in Vygotsky's theory of learning and school instruction. In: KOZULIN, A. et al. (Ed.), Vygotsky's educational theory in cultural context. Cambridge: Cambridge University Press, 2003. p. 39-64.

CHARLOT, B. Relação com o saber, formação dos professores e globalização. Porto Alegre: ArtMed, 2005.

COSTA, E.; AFONSO, N. Os instrumentos de regulação baseados no conhecimento: $o$ caso do programme for international student assessment (PISA). Educação \& Sociedade. Educ. Soc. vol.30 no.109 Campinas, 2009.

DAVÍDOV, V. V. Tipos de generalización en la enseñanza. Havana: Editorial Pueblo y Educación, 1983.

Problemas do ensino desenvolvimental - a experiência da pesquisa teórica e experimental na psicologia. Textos publicados na Revista Soviet Education, August/VOL XXX, N 8, sob o título "Problems of Developmental Teaching. Tradução de José Carlos Libâneo e Raquel A. M. da Madeira Freitas, 1986.

. La enseñanza escolar y el desarrollo psiquico. Moscou: Progresso, 1988.

What is real learning activity? In: M. Hedegaard and J. Lompscher (Eds.), Learning, activity and development. Aarhus: Aarhus University Press, 1999. EDLER, C. R. A integração de pessoas com deficiência. São Paulo:Memnon, 1997.

FAGUNDES, T. B.; MATTOS, C. L. de. Tarefa escolar: ferramenta pedagógica para a aprendizagem ou cumprimento do dever do(a) aluno(a)? Espaço do Currículo, v.1, n.2, pp.33-54, Março-2009.

FERNANDEZ, A. P. de O.; PONTES, F. A. R.; SILVA, S. S. C.; LIMA, M. B. S.; SANTOS, C; O; dos. Envolvimento parental na tarefa escolar. Revista Quadrimestral da Associação Brasileira de Psicologia Escolar e Educacional, SP. Volume 18, Número 3, Setembro/Dezembro de 2014: 529-536.

FRANCO, O. C. M. Práticas familiares em relação ao dever de casa. UFMG, 2002. Dissertação de Mestrado.

FREIRE, P. Educação como Prática da Liberdade. Rio de Janeiro: Paz e Terra, 1967.

FREITAS, R. A. M. Da M. \& ROSA, S. V. L. Ensino Desenvolvimental: contribuições à superação do dilema da didática. Educação \& Realidade, Porto Alegre, v. 40, n. 2, p. 613 627, abr./jun. 2015.

FRIGOTTO, G. (Org.) ; ORG, G. F. (Org.) ; Acácia Kuenzer (Org.) ; GENTILI, P. (Org.). Educação e crise do trabalho. 11ª . ed. Petrópolis-RJ: Vozes, 2013. 
INEP. Instituto Nacional de Estudos e Pesquisas Educacionais Anísio Teixeira. PISA, 2011. Disponível em: http://www.inep.gov.br/internacional/novo/PISA/resultados.htm:

Consultado em setembro de 2015.

LENOIR, Y. Médiation cognitive et mediation didactique. In: RAISKY, C. e Caillot, M. Au-delà des didactiques, le didactique. Paris, Bruxelas: De Boeck e Larcier, 1996.

LIBÂNEO, J. C. A didática e a aprendizagem do pensar e do aprender: a teoria históricocultural da atividade e a contribuição de V. Davídov. Revista Bras. De Educação, Rio de Janeiro, n.27, p. 5-24, dez. 2004.

. A didática e as exigências do processo de escolarização: formação cultural e científica e demandas das práticas socioculturais. In: Anais do III Encontro Estadual de Didática e Prática de Ensino (EDIPE), Anápolis, 2009.

MIRANDA, M. Jr. O Ensino Desenvolvimental e a Aprendizagem do Voleibol. Verlag / Editora Novas Edições Acadêmicas, 2013.

NOGUEIRA, M. G. Tarefa de casa - uma violência consentida? São Paulo: Edições Loyola, 2002.

NOGUEIRA, M. G. Família e escola na contemporaneidade: os meandros de uma relação. XXVIII Reunião Anual da Anped, Caxambu/MG, 2005.

NÓVOA, A. Professores: imagens do futuro presente. Educa: Lisboa, 2009.

RESENDE, T. .F. Dever de casa: questões em torno de um consenso. Projeto Integrado de Pesquisa do observatório Sociológico família-Escola. Disponível em

http://www2.unifap.br/gpcem/files/2011. Acesso em 20 de setembro de 2015.

ROSSI, M. A. G. L.; DE PAULA, O. As habilidades de leitura avaliadas pelo pisa e pela prova brasil: reflexões para subsidiar o trabalho do professor de língua portuguesa. Fórum Linguístico, Florianópolis, v. 9, n. 1, p. 34-46, jan./mar, 2012. Disponível em http://dx.doi.org/10.5007/. Acesso em 15 de setembro de 2015.

SADOVSKY, P. Falta Fundamentação Didática no Ensino da Matemática. Nova Escola. São Paulo, Ed. Abril, Jan./Fev. 2007.

SOARES, F. C. C. O ensino desenvolvimental e a aprendizagem de matemática na primeira fase do ensino fundamental / Fernanda Chaves Cavalcante Soares. - 2007. $118 \mathrm{f}$. Dissertação (Ms) - Universidade Católica de Goiás, Mestrado em Educação, 2007. Universidade Católica de Goiás / Programa de Pós-Graduação em Educação. 2011. Disponível em http://tede.biblioteca.pucgoias.edu.br/tde. Acesso 29 de set de 2015.

VIGOTSKI, L. S. Linguagem, desenvolvimento e aprendizagem. São Paulo: Ícone, 1994. . A formação social da mente. Trad. José Cipolla Neto, Luís Silveira Menna Barreto, Solange Castro Afeche. - $7^{\mathrm{a}}$ ed. - São Paulo: Martins Fontes, 2007.

Notas

\footnotetext{
${ }^{1}$ Este texto faz parte da nossa produção desenvolvida no Programa Nacional de Pós-doutorado (PNPD) da Comissão de Aperfeiçoamento de Pessoal de Nível Superior (CAPES), junto ao Programa de Pós-graduação em Educação (PPGE), Campus Pantanal (CPAM) da Universidade Federal do Mato Grosso do Sul (UFMS).

${ }^{2}$ Professor efetivo da Escola Superior de Educação Física e Fisioterapia do Estado de Goiás (ESEFFEGO) / Universidade Estadual de Goiás (UEG) e Pontifícia Universidade Católica de Goiás (PUCGO). E-mail: madejr@ig.com.br

Recebido: março-16 Aprovado: setembro-16
} 